\title{
Risk Factors for Central Venous Line Complications Versus Umbilical Veous Catheter in Premature Neonates Admitted to El Warak Centeral Hospital Neonatal Intesive Care Unit
}

O.A.ELfeki ${ }^{1}$, E.H.Assar ${ }^{1}$, S.H.Goda ${ }^{1}$, A.A.Torki ${ }^{2}$ and M.M.Mohammed ${ }^{1}$

${ }^{1}$ Pediatrics Dept., Faculty of Medicine, Benha Univ., Benha, Egypt

${ }^{2}$ Radiology Dept., Faculty of Medicine, Benha Univ., Benha, Egypt

E-Mail: MaiMohsen6@gmail.com

\begin{abstract}
peripherally inserted central catheters (PICCs) are routinely used in term and preterm infants to provide intravenous access for prolonged therapy and parenteral nutrition. They are known to reduce the complications associated with the conventionally used central catheters. PICCs can be conveniently inserted at the bedside without the need for surgical intervention. The point of the available investigation might have been with assess those danger figures to vital venous offering difficulties versus umber venous catheter over preterm neonates admitted to el Warak national clinic in neonatal seriousness Furthermore its result. This Prospective observational consider required been conveyed out in NICUs toward el Warak national clinic between December2018 Also december 2019, those ponder might have been conveyed out ahead 100 newborns ( preterm) that were admitted will nicu by diverse result in Also have focal embedded vascular catheter (Umbilical venous catheter Also vital veous cathter). Comes about of the study uncovered that crp Also PTT were altogether higher in CVC one assembly contrasted with UVC. However, TLC, platelets check Also HCT qualities were more level same time inr might have been higher On CVC gathering contrasted with UVC bunch without measurable hugeness distinction Also direct might have been the The greater part incessant condition "around the two groups, In awful condition might have been All the more incessant over CVC assembly. However, there may be no huge Contrast the middle of the Assemblies in regards general condition. There might have been no noteworthy distinction in the occurrence about CABSI the middle of altogether preterm neonates who accepted a CVC alternately UVC Concerning illustration those elementary mode about venous get after conception. A prospective randomized regulated trial will be advocated will further aide act viewing essential venous get What's more diminishment from claiming spoiling.
\end{abstract}

Keywords: PICCs, CVC, UVC, Neonatal intensive care unit, CABSI.

\section{Introduction}

Those sorts of focal venous catheter CVC regularly utilized done pediatrics neonatology would peripherally embedded national catheters (PICC), national insertion catheters, Furthermore umber venous catheters (UVC). These units permit constant organization of intravenous liquids and medications, parenteral nutrition, hemodynamic monitoring, Also over exactly instances transfusion of blood products, contingent upon the catheter gauge and the patient's agdistis [1]. On neonatal emergency unit units (NICUs), UVCs are recommended for newborns Throughout the primary days of life, as the insertion is moderately basic and carries a low hazard of related difficulties [2]. The danger figures for promptly sepsis, characterized Likewise the individuals that happen inside the Initially $48 \mathrm{~h}$ about life, need aid identified with the underlying infection Also of the caliber of the consideration gave. Viewing late sepsis, which happens after those Initially $48 \mathrm{~h}$ for life, it is identified with those backhanded contact with those defiled clinic environment, for low conception weight, the utilization about obtrusive units for example, such that CVC and mechanical ventilation (MV), deferred start about enteral nutrition, prolonged utilization of parenteral nutrition, and difficulties about prematurity, for example, such that patent ductus arteriosus What's more necrotizing enterocolitis, which might oblige surgical intercession [3].

\section{Materials and methods}

This Prospective observational investigation required been conveyed out in NICUs at el WARAK national healing center between December2018 Also december 2019, for those endorsement of the moral council for staff about medicine-Benha school Also guardian of the neonates .

The study might have been conveyed out with respect to 100 newborns ( preterm) that were admitted to nicu by distinctive reason and need national embedded vascular catheter (Umbilical venous catheter Furthermore national veous cathter). They met all consideration Furthermore prohibition criteria to enlistment under this contemplate .

Incorporation criteria: Preterm Neonates (neonates The following 37 finished weeks), both sexual orientation Also Critically sick preterms that will necessity vital cathetrizations .

Avoidance criteria: Neonates not inserting vascular catheter

Information identified with the newborn: history taking: (mode from claiming delivery, gestational age, sex, confirmation diagnosis, prenatal history, natal history, postnatal history, gang history, maternal history). All examination of the neonate including: estimations (length, weight, head, abdominal Also midsection circumference), indispensable indications (heart rate, respiratory rate, temperature Also blood pressure) Also all condition What's more action What's more neonatal reflexes (Moro Also Suckling). 
Systemic examination: (chest, heart, abdominal, CNS). Neighborhood examination toward webpage of insertion. Clinical Furthermore lab indications suggesting sepsis (presence of two or A greater amount of those taking after clinical criteria): bolstering prejudice (feedings held to more amazing over 24 hours) to an baby who needed been tolerating propelling alternately full encourages to three times. Extreme apnea requiring sure weight ventilation. Expansion Previously, number for apneic scenes half In a 24 hour period to a newborn child who required been extubated Also stable for three times. Immature/total neutrophil (I:T) proportion more excellent over 0. 2. Increment clinched alongside ventilatory help Also FiO2 25\% starting with benchmark. Torpidly or hypotonia. Temperature unsteadiness (hypothermia alternately hyperthermia). Hyperglycemia (180mg/dL). Abnormal white platelet number (less over 5000 or more than 20000). Platelet number $(<150000$ phones for every $\mathrm{mm} 3$.(

Lab investigation:. (CBC with differential Also CRP): PT,PTT,INR, Radilogical investigations, Plain midsection X-beam should affirm those position for tip from claiming focal venous catheter Also identify of other complications, Plain midsection and abdomen $\mathrm{x}$ beam will affirm tip for umber venous catheter What's more identify of different difficulties Furthermore ultrasonography (Sonar) with affirm tip from claiming vital catheter and difficulties. Dopplar ultrasonography should catch up muddling venous catheter. Reverberation on catch up muddling venous catheter.

\subsection{Measurable analysis}

Information might have been entered on the PC utilizing "Microsoft office exceed expectations
Software" system (2010) for windows, that point exchanged of the measurable one bundle about social science programming program, adaptation 23 (SPSS) to a chance to be statistically investigated .

\section{Results}

Effects. No noteworthy Contrast discovered the middle of the two Assemblies in regards GA, sex What's more conveyance. Table (1). This table indicates that those CVC assembly need huge higher values in regards heart rate, respiratory rate, Also temperature contrasted with UVC bunch. Table (2). Direct might have been those practically incessant state "around the two groups, In awful condition might have been All the more incessant in CVC one assembly. However, there is no noteworthy distinction between those aggregations in regards all state Table (3). CVC patients were fundamentally a greater amount incessant in regards to difficulties Furthermore non-selective evacuation about catheter. Period for catheter might have been fundamentally higher clinched alongside over CVC assembly Table (4). Those The greater part muddling Around those two aggregations might have been CLABSI. However, there is no critical distinction between those Assemblies Table (5). The The majority motivation behind from claiming non-selective evacuation for catheter "around the two bunches might have been contamination. However, there is no huge Contrast the middle of the bunches Table (6). GA, female gender, sepsis presence, CVC, apgar score Furthermore more span for catheter were a critical hazard component to muddling related catheter Table (7).

Table (1) Demographic characteristics of the two studied groups

\begin{tabular}{|c|c|c|c|c|c|}
\hline & & $\begin{array}{l}\text { UVC } \\
(n=46)\end{array}$ & $\begin{array}{l}\text { CVC } \\
(n=54)\end{array}$ & $\mathrm{t} / \chi^{2}$ & p-value \\
\hline \multicolumn{2}{|c|}{ Gestational age (week) } & $33.07 \pm 2.07$ & $32.87 \pm 1.97$ & 0.481 & 0.631 \\
\hline \multicolumn{2}{|c|}{ Mean \pm SD } & $2-48$ & $3-53$ & & \\
\hline \multicolumn{6}{|c|}{ Range } \\
\hline \multirow[t]{2}{*}{ Sex } & Female & $24(52.2 \%)$ & $19(35.2 \%)$ & 2.925 & 0.087 \\
\hline & Male & $22(47.8 \%)$ & $35(64.8 \%)$ & & \\
\hline \multirow[t]{2}{*}{ Delivery } & VD & $9(19.6 \%)$ & $19(35.2 \%)$ & 7.551 & 0.374 \\
\hline & CS & $37(80.4 \%)$ & $35(64.8 \%)$ & & \\
\hline
\end{tabular}

Table (2) Vital data of the two studied groups.

\begin{tabular}{lllll}
\hline & $\begin{array}{l}\text { UVC } \\
(\mathbf{n}=\mathbf{4 6})\end{array}$ & $\begin{array}{l}\text { CVC } \\
(\mathbf{n = 5 4})\end{array}$ & t & p-value \\
\hline $\begin{array}{l}\text { HR (b/min) } \\
\text { Mean } \pm \text { SD }\end{array}$ & $135.17 \pm 8.02$ & $140.63 \pm 17.92$ & 1.908 & 0.059 \\
$\begin{array}{l}\text { RR (c/min) } \\
\text { Mean } \pm \text { SD } \\
\text { Temperature }\left({ }^{\circ} \mathbf{C}\right)\end{array}$ & $49.93 \pm 9.2$ & $54.33 \pm 10.58$ & 2.198 & 0.030 \\
Mean \pm SD & $37.07 \pm .278$ & $37.16 \pm .337$ & 1.446 & 0.151 \\
\hline
\end{tabular}


Table (3) General condition between the two groups.

\begin{tabular}{|c|c|c|c|c|c|c|}
\hline & \multirow{2}{*}{$\begin{array}{r}\text { UVC }(n=46) \\
\mathbf{N}\end{array}$} & \multicolumn{3}{|c|}{$\operatorname{CVC}(n=54)$} & \multirow[t]{2}{*}{$\chi^{2}$} & \multirow[t]{2}{*}{ P-value } \\
\hline & & $\%$ & $\mathbf{N}$ & $\%$ & & \\
\hline Good & 3 & 6.5 & 3 & 5.6 & 4.496 & 0.213 \\
\hline Moderate & 28 & 60.9 & 24 & 44.4 & & \\
\hline Mild & 6 & 13 & 6 & 11.1 & & \\
\hline Bad & 9 & 19.6 & 21 & 38.9 & & \\
\hline
\end{tabular}

Table (4) Catheter characteristics and outcome among the two groups.

\begin{tabular}{|c|c|c|c|c|c|c|}
\hline & \multicolumn{2}{|c|}{ UVC $(n=46)$} & \multicolumn{2}{|c|}{$\operatorname{CVC}(n=54)$} & \multirow[t]{2}{*}{$\chi^{2}$} & \multirow[t]{2}{*}{$\mathbf{P}$} \\
\hline & $\mathbf{N}$ & $\%$ & $\mathbf{N}$ & $\%$ & & \\
\hline Complications & 9 & 19.6 & 23 & 42.6 & 6.05 & .014 \\
\hline Non-elective removal & 7 & 15.2 & 21 & 38.9 & 6.91 & .009 \\
\hline Death & 3 & 6.5 & 7 & 13 & 1.145 & .285 \\
\hline Length of catheter & & & & & MW & .000 \\
\hline Mean \pm SD & \multirow{2}{*}{\multicolumn{2}{|c|}{$\begin{array}{c}9.33 \pm 4.25 \\
2-16\end{array}$}} & \multicolumn{2}{|c|}{$27.52 \pm 12.64$} & 272.5 & \\
\hline Range & & & \multicolumn{2}{|c|}{$4-46$} & & \\
\hline
\end{tabular}

Table (5) Complications related to Catheter among the two groups.

\begin{tabular}{lcccccc}
\hline & UVC $(\mathbf{n = 9})$ & \multicolumn{3}{c}{$\mathbf{C V C}(\mathbf{n = 2 3})$} & & \multirow{2}{*}{ P-value } \\
\cline { 2 - 6 } & $\mathbf{N}$ & $\mathbf{\%}$ & $\mathbf{N}$ & $\mathbf{\%}$ & & \\
\hline Thrombosis & 0 & 0 & 3 & 13.1 & 2.635 & .105 \\
CLABSI & 3 & 33.3 & 10 & 43.5 & 3.161 & .075 \\
Pneumothorax & 0 & 0 & 1 & 4.3 & .860 & .354 \\
Extravasation & 2 & 22.2 & 2 & 8.7 & .027 & .870 \\
Bleeding & 1 & 11.1 & 1 & 4.3 & .013 & .909 \\
Occlusion & 1 & 11.1 & 2 & 8.7 & .200 & .655 \\
Phlebitis & 1 & 11.1 & 1 & 4.3 & .013 & .909 \\
Leakage & 1 & 11.1 & 2 & 8.7 & .200 & .655 \\
Pleural effusion & 0 & 0 & 1 & 4.3 & .860 & .354 \\
\hline
\end{tabular}

Table (6) Reasons of non-selective removal among the two groups.

\begin{tabular}{|c|c|c|c|c|c|c|}
\hline & \multicolumn{2}{|c|}{ UVC (n=7) } & \multicolumn{2}{|c|}{ CVC $(n=21)$} & \multirow[t]{2}{*}{$\chi^{2}$} & \multirow[t]{2}{*}{ P-value } \\
\hline & $\mathbf{N}$ & $\%$ & $\mathbf{N}$ & $\%$ & & \\
\hline Thrombosis & 0 & 0 & 3 & 14.3 & 2.021 & .117 \\
\hline Infection & 3 & 33.3 & 10 & 47.6 & 3.231 & .062 \\
\hline Pneumothorax & 0 & 0 & 1 & 4.8 & .764 & .435 \\
\hline Displacement & 2 & 22.2 & 2 & 9.5 & .032 & .824 \\
\hline Occlusion & 1 & 11.1 & 1 & 4.8 & .164 & .531 \\
\hline Phlebitis & 0 & 0 & 1 & 4.8 & .764 & .435 \\
\hline Leakage & 1 & 11.1 & 2 & 9.5 & .216 & .495 \\
\hline Pleural effusion & 0 & 0 & 1 & 4.8 & .764 & .435 \\
\hline
\end{tabular}

Table (7) Multivariate logistic regression analysis to determine the risk factors for complication.

\begin{tabular}{lllll}
\hline & OR & S.E. & Sig. & $\begin{array}{l}\text { 95\% Confidence } \\
\text { Interval }\end{array}$ \\
\hline GA & 1.745 & .152 & .024 & $1.021-1.962$ \\
Female & 2.413 & .089 & .011 & $.649-3.646$ \\
Sepsis & .913 & .062 & .017 & $.716-1.032$ \\
CVC & 1.110 & .161 & .006 & $.816-1.264$ \\
Length of catheter & 2.694 & .046 & .013 & $.495-3.642$ \\
CHD & .919 & .015 & .106 & $.394-1.267$ \\
Apgar score & 2.307 & .072 & .032 & $1.226-3.112$ \\
\hline
\end{tabular}




\section{Discussion}

Focal catheters would prescribed in perspective of convenience, cost-benefit, Also fewer difficulties over fringe transient venous catheters, Also skin tunneled bound catheters [4].

Venous get will be crucial in the management for preterm babies particularly to giving parenteral sustenance and medications Also thus, secure venous get is urgent clinched alongside their management. Really preterm neonates who get sustenance through An vital catheter have been showed up for need fundamentally higher weight gain, shorter doctor's facility stay, Also easier rates from claiming spoiling compared for babies for various fringe focuses for venous right [5].

With respect to dissection of the study findings, as view demographic aspects of the mulled over cases, we discovered that intend \pm sd of gestational agdistis for UVC will be $33.07 \pm 2.07$ Also $32.87 \pm 1.97$ weeks in CVC, Furthermore there might have been no huge Contrast discovered between the two gatherings in regards to GA, sex and conveyance.

Thinking about of the study about [6] done which they accounted that mean \pm sd about gestational period to UVC might have been $28.7 \pm 2$. 3 weeks Also was28. $5 \pm 1$. 99weeks done CVC, and in understanding with our consider they found that there might have been no huge Contrast discovered the middle of the two aggregations viewing GA, sex What's more conveyance.

G. Dubbink-Verheij et al., [7] news person that 2,986 neonates about 34 or additional weeks' gestation were admitted should our nicu. Those edge from claiming 34 weeks gestational period might have been decided in view FVCs would not put to neonates of easier gestational ages at our nicu.

Furthermore, the available contemplate uncovered that CVC patients were altogether additional incessant viewing difficulties Furthermore non-selective evacuation for catheter. Period about catheter might have been altogether higher to clinched alongside CVC assembly.

In understanding for our findings, an alternate contemplate for [8] accounted for that non-umbilical vital venous catheters indicated a essentially higher frequency for difficulties over umber ones.

On the different hand, the available study uncovered that those The greater part muddling "around those two bunches might have been CLABSI. However, there may be no huge distinction between those aggregations.

In regards complications, $46.4 \%$ about CVCs in the consider about [9] needed unfriendly occasions. These were encountered "around $44.3 \%$ from claiming UVCs and $52.8 \%$ from claiming CVLs. On the other hand, 20. $1 \%$ about UVCs Also 31. 7\% about PICCs were muddled in the study of [10]. The practically incessant difficulties "around UVCs to our examine were clinical sepsis (18. 7\%), trailed Toward spillage (12.6\%), and CLABSI (11. 7\%), same time On [10] they were clinical sepsis, trailed Toward CLABSI, At that point disengagement $(10.7 \%, 4.3 \%$, and $2.9 \%$ respectively). On the other hand, [10] ponder CLABSI originated over 1 st spot (11. 1\%), emulated Toward clinical sepsis, and hindrance (7. $9 \%$ each). Klipsiella might have been the mossycup oak every now and again cosmopolitan living being On our study (49. 4\% from claiming UVC related CLABSI, and the absolute case for cc related CLABSI), same time coagulase negative staphylococcus might have been those the vast majority every now and again cosmopolitan living being for [10] investigation (66. 7\% from claiming UVC Also cc related CLABSI).

Past investigations bring recognized danger figures for difficulties for CVC On neonates. These danger figures included junior age, seriousness of illness, catheter stay time, catheter tip position, and catheter insertion site [11], At reports clinched alongside egypt neonates are uncommon. Recognizing modifiable danger figures of difficulties will be particularly vital Likewise clinicians fill in will forestall catheter difficulties.

In the available study, Similarly as see general conditions, moderate might have been those the vast majority incessant condition "around those two groups, In awful condition might have been a greater amount incessant clinched alongside CVC one assembly. However, there will be no critical Contrast between those gatherings in regards to general state.

Over past investigations for [12] accounted that premature birth, seriousness for newborn child condition, CVC span tip position, Also webpage about vital catheter insertion have been proposed on be danger figures about nonselective evacuation. A expanded rate about difficulties need been recorded for non-central catheter tips. Moreover, elements for example, little vespula vulgaris size, diminished blood stream rate, turbulent flow, and endothelial damage would acknowledged on help these difficulties.

\section{Conclusion}

This study indicates that among preterm neonates born at less than 34 weeks' gestation, the type of primary central vascular access, whether it was a UVC or CVC, The most complication among the two groups was CLABSI. However, there is no significant difference between the groups. This study indicated that GA, female gender, sepsis presence, CVC, Apgar score and longer duration of catheter were a significant risk factor for complication related catheter.

\section{References}

[1] L. Wang, Z.S. Liu , C.A. Wang, Malposition of central venous catheter: presentation and management. Chin Med J; vol 129(2), PP.227-34, 2016.

[2] Stacker and Berger. Arterial and central venous catheters in neonates and infants. Anaesthesist, Vol.55(8), PP.873-82, 2006. 
[3] C. Geffers, A .Gastmeier, F.Schwab, Use of central venous catheter and peripheral venous catheter as risk factors for nosocomial bloodstream infection in very-low-birth-weight infants. Infect Control Hosp Epidemiol, Vol.31, PP.395-401, 2010

[4] A.R.Dongara, D.V.Patel, S.M.Nimbalkar, N.Potana, A.S. Nimbalkar, Umbilical Venous Catheter Versus Peripherally Inserted Central Catheter in Neonates: A Randomized Controlled Trial. J. Trop. Pediatr ; Vol.63, PP.374-379, 2017.

[5] D.F. Yumani, F.A. van den Dungen, M.M. van Weissenbruch, Incidence and risk factors for catheter-associated bloodstream infections in neonatal intensive care. Acta Paediatr, Vol.102(7), PP. 293-298, 2013.

[6] A.Konstantinidi, R.Sokou, P.Panagiotounakou, M.Lampridou, S.Parastatidou, K.Tsantila, Umbilical Venous Catheters and Peripherally Inserted Central Catheters: Are They Equally Safe in VLBW Infants? A Non-Randomized Single Center Study. Medicina (Kaunas, Lithuania); Vol.55(8), PP. 442 -10, 2019.

[7] G. Dubbink-Verheij, Vincent Bekke, C. M. Iris Pelsma, W. Erik van Zwet, E. H. J. Vivianne ,
Bloodstream Infection Incidence of Different Central Venous Catheters in Neonates: A Descriptive Cohort Study, Front. Pediatr; Vol.10(3), PP. 14, 2017.

[8] B. N.Soares, S.Pissarra, A. L. Rouxinol-Dias, Complications of central lines in neonates admitted to a level III Neonatal Intensive Care Unit. The Journal of Maternal-Fetal \& Neonatal Medicine; Vol.31(20), PP. 2770-2776, 2018.

[9] Ismail. study of different neonatal vascular accesses in neonatal intensive care units in different universities hospitals in Egypt al-Azhar Assiut medical journal AAMJ, Vol.13 (2) , PP.127, 2015 .

[10] M. Jeng, Y. Lee, P. Tsao, W.Soong, Neonatal air leak syndrome and the role of high-frequency ventilation in its prevention. J Chinese Med Assoc, Vol.75(11), PP.551-9, 2012.

[11] X.Li, H.Wang, Y.Chen, Z.Yuan, Multifactor analysis of malposition of peripherally inserted central catheters in patients with cancer. Clinical Oncology Nursing J;Vol. 19(4) ,PP. 70-73, 2015.

[12] A. M.Milstone, N. G.Reich, S.Advani, Catheter dwell time and clabsis in neonates with piccs: A multicenter cohort study. Pediatrics, Vol.132(6), PP. 1609-1615, 2013. 